\title{
STUDY OF FIRE CHARACTERISTICS OF INDUSTRIAL DUST
}

\author{
Zuzana SZABOVÁ ${ }^{1}$, Richard KURACINA ${ }^{1}$ \\ ${ }^{1}$ SLOVAK UNIVERSITY OF TECHNOLOGY IN BRATISLAVA, \\ FACULTY OF MATERIALS SCIENCE AND TECHNOLOGY IN TRNAVA, \\ INSTITUTE OF INTEGRAL SAFETY \\ UliCA JÁnA BotTu 2781/25, 91724 TRNAVA, SLOVAKIA \\ e-mail: zuzana.szabova@stuba.sk,richard.kuracina@stuba.sk \\ Received: 30.04.2019, Accepted: 18.06.2019, Published: 25.07.2019
}

\begin{abstract}
The article deals with the determination of fire characteristics of industrial dust samples. Particle size granulometry and determination of explosion parameters according to EN 14034 (Lower Explosion Limit LEL, $P_{\max }, K_{s t}$ ) are presented. The minimum ignition temperatures of the dust layer and dispersed dust from the hot surface according to EN ISO / IEC 80079-20-2: 2016 were measured. It was found that LEL is $60 \mathrm{~g} . \mathrm{m}^{-3}, P_{\max }$ is $8.61 \mathrm{bar}$, and $K_{\text {st }}$ is $89 \mathrm{bar} . \mathrm{s}^{-}$ ${ }^{1} . m$. The minimum ignition temperature (MIT) of dust layer is $280^{\circ} \mathrm{C}$ and the minimum ignition temperature of dispersed dust is $400^{\circ} \mathrm{C}$.
\end{abstract}

\section{Key words}

Dust layer, dust explosion, minimum ignition temperature, dust cloud

\section{INTRODUCTION}

In almost all industrial plants where mechanical processes such as cutting, grinding, milling, slicing etc. of solids are being carried out, dust starts accumulating. Its presence gives rise to a hazard, as the appropriate ignition sources can cause fire or explosion of dust, which may as a consequence lead to death or body harm. Moreover, those phenomena can cause considerable property losses. In the event of a fire, the most frequent cause of death or injury and loss of property is thermal radiation and toxic products of combustion as well as thermal decomposition. In case of explosion, this comprises a pressure wave and fragments of materials. [1] Many scientific papers $([2,3,4,5,6,7])$ are concerned with investigating the fire characteristics of industrial dust.

\section{Sample preparation}

A sample of industrial dust arising from the sanding of wood veneer was supplied in a powder form. The sample did not require any particle size preparation (milling). The sample was subjected to sieving to obtain the fractions needed to determine MIT and to determine the weight fractions of the individual fractions. 


\section{Determination of explosion characteristics}

For measurement of explosion characteristics, a modified chamber KV 150-M2 was used. Dust clouds in this unit are carried out mechanically. From the tank of the volume 5.5 litres, compressed air is transmitted by fast opening of an electromagnetic valve to inner space of the chamber of 291 litre volume. The sample is located on a plate and spread by the compressed air at the pressure of 9.5 bar. The compressed air is directed to the sample through the metal profiled sheeting. The sample is ignited by a chamber nitrocellulose igniter after the spreading the sample. The igniter works with a fuse head. Immediate ignition of nitrocellulose is achieved by the power source with parameters $60 \mathrm{~V} \mathrm{DC}$ and $5.5 \mathrm{~A}$, which is supplied to the fuse head and results in an immediate burning. Ignition energy of the nitrocellulose used in the initiator is $2 \times 5 \mathrm{~kJ}$.

Ignition of the dust and dispersion of the dust is timed using a solid state timing relay. The relay is set to a fixed time interval between opening the fast opening valve and with the connecting power to the clamps of initiator. Time delay was set on $240 \mathrm{~ms}$. The pressure changes inside the chamber are recorded through pressure transducer of the voltage output $(0$ $10 \mathrm{~V}$ ) and the maximum measurable overpressure value of $20 \mathrm{bar}$. The pressure transducer is powered by a stabilized $24 \mathrm{~V} \mathrm{DC}$ source. Response time of pressure transducer is $0.5 \mathrm{~ms}$ and the current value is recorded through the datalogger. The measured sample was industrial dust. Particle size of the sample is listed in Table 2. Measurement of parameters was carried out on the apparatus described above. The igniter was nitrocellulose of a weight from $1.25 \mathrm{~g}$. The voltage in the circuit was measured by a high-speed data logger. The values were recorded at the rate of 10000 values/second. Recording of the pressure changes during the explosion of dust clouds was measured within the concentrations range $60-1000 \mathrm{~g} / \mathrm{m}^{3}$. [8]

\section{Determination of the minimum ignition temperature of a dust cloud}

Small quantities of dust were blown through a heated furnace and ignition was detected by visual inspection. The test material was dispersed in the furnace by an air blast and the dust quantity was from 0.1 and $0.2 \mathrm{~g}$. The dust was dispersed by the air at the pressure of 10, 20 and $50 \mathrm{kPa}$. The first test was performed at the temperature $450{ }^{\circ} \mathrm{C}$ and pressure $50 \mathrm{kPa}$.

If a burst of flame was seen below the end of the furnace tube, it was considered as an ignition. The minimum ignition temperature was recorded as the lowest temperature of the furnace where ignition was obtained using the above-mentioned procedure minus $20 \mathrm{~K}$ for furnace temperatures above $300{ }^{\circ} \mathrm{C}$ and minus $10 \mathrm{~K}$ for furnace temperatures at or below 300 ${ }^{\circ} \mathrm{C}$. The particle size of the sample was below $71 \mu \mathrm{m}$. [9]

\section{Determination of the minimum ignition temperature of a dust layer}

The apparatus consists of a heated plate and a dust ring. The heated surface consists of a circular metal plate and provides a working area of $200 \mathrm{~mm}$ in diameter and not less than $20 \mathrm{~mm}$ in thickness. The heated surface and its control device satisfy the following performance requirements:

- the heated surface is capable of attaining the maximum temperature of $400{ }^{\circ} \mathrm{C}$,

- the temperature of the heated surface is constant within $\pm 5 \mathrm{~K}$ thorough the period of the test,

- a thermocouple is connected to a temperature recorder to record the temperature of the surface during the test.

The dust layer was formed without compressing the layer. The ring diameter was $100 \mathrm{~mm}$ and the depth of the ring was $5.0 \mathrm{~mm} \pm 0.1 \mathrm{~mm}$.

The dust layer temperature was measured within the layer at a height of $3 \mathrm{~mm}$ from the surface of the plate at the centre of the dust layer. 
Ignition was considered to have occurred if:

- a visible glowing or laming is observed; or

- a temperature of $450{ }^{\circ} \mathrm{C}$ is measured in the dust layer; or

- a temperature rise of $250 \mathrm{~K}$ above the temperature of the heated plate is measured in the dust layer.

If no further temperature increase was apparent after a period of $30 \mathrm{~min}$. the test was terminated ad repeated at a higher temperature. Testing was continued until the temperature was found to cause ignition in the layer. The particle size of sample was below $200 \mu \mathrm{m}$. [9]

\section{RESULTS AND DISCUSSION ON RESULTS}

\section{Characterisation of sample}

The sample was used as supplied. Tab. 1 shows the particle size distribution of the industrial dust sample with the median value and weighed average particle size.

\begin{tabular}{|l|l|l|}
\hline \multicolumn{3}{|l|}{$\begin{array}{l}\text { Table 1 Particle size distribution of industrial dust sample } \\
\text { (total mass of sample for sieving 228.32 g) }\end{array}$} \\
\hline \hline Particle size & Weight of fraction [g] & Fraction [\%] \\
\hline \hline$>500 \mu \mathrm{m}$ & 6.28 & 2.75 \\
\hline $250-500 \mu \mathrm{m}$ & 3.51 & 1.54 \\
\hline $200-250 \mu \mathrm{m}$ & 2.56 & 1.12 \\
\hline $150-200 \mu \mathrm{m}$ & 3.91 & 1.71 \\
\hline $90-150 \mu \mathrm{m}$ & 10.35 & 4.53 \\
\hline $56-90 \mu \mathrm{m}$ & 8.20 & 3.59 \\
\hline $56-71 \mu \mathrm{m}$ & 131.13 & 57.43 \\
\hline $0-56 \mu \mathrm{m}$ & 62.38 & 27.32 \\
\hline \hline median value: & $50 \mu \mathrm{m}$ \\
\hline \hline average particle size & $77.5 \mu \mathrm{m}$ \\
\hline
\end{tabular}

\section{Explosion characteristics}

The values of pressure depending on the time which were obtained by measurement are shown in Figures 1 and 2. From the results suggest that with increasing the concentration of the dust, the pressure value and the pressure rise value in the chamber also increase. 


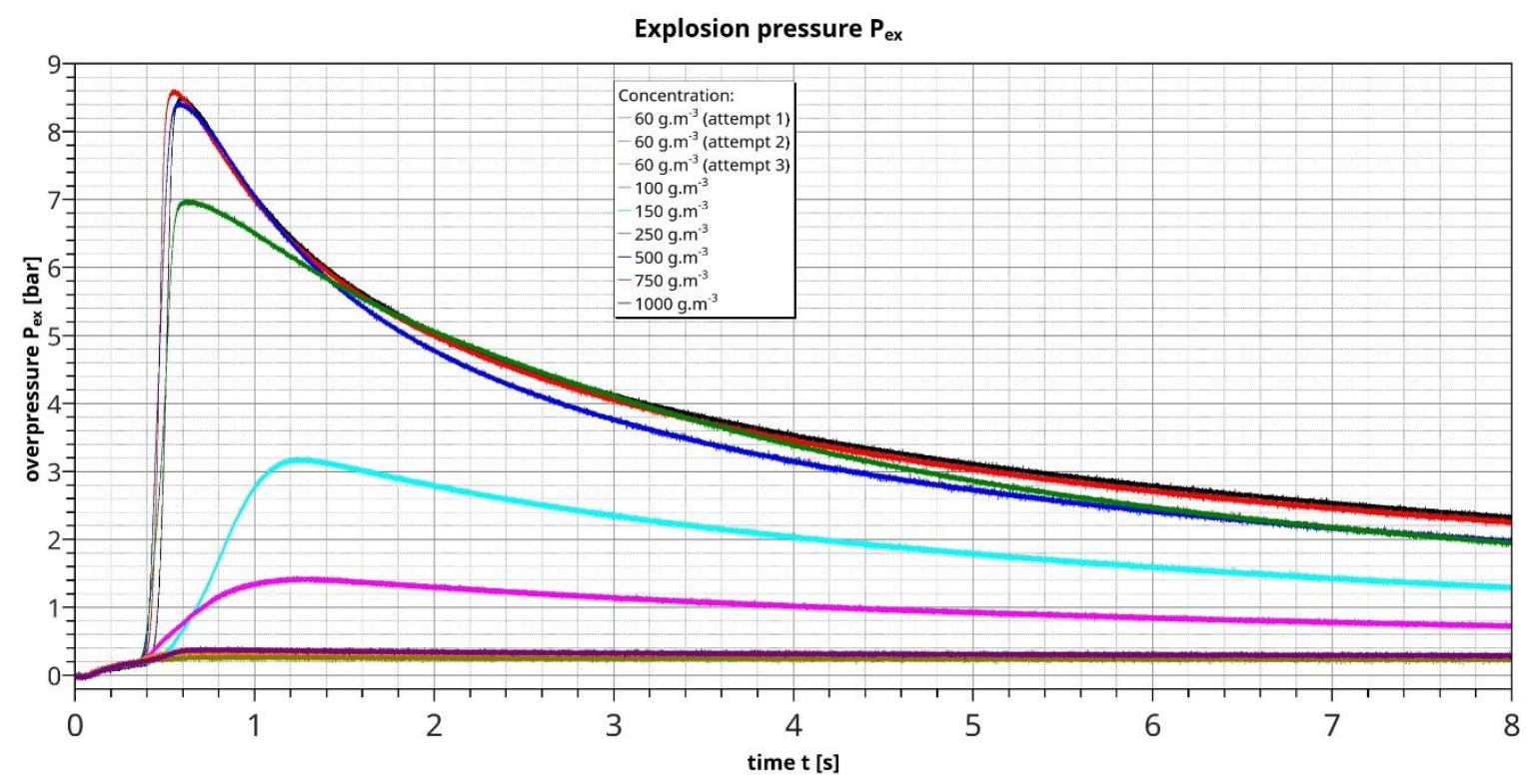

Fig. 1 Determination of the maximum explosion pressure $P_{\max }$ and Lower Explosion Limit (LEL) during explosion of industrial dust sample

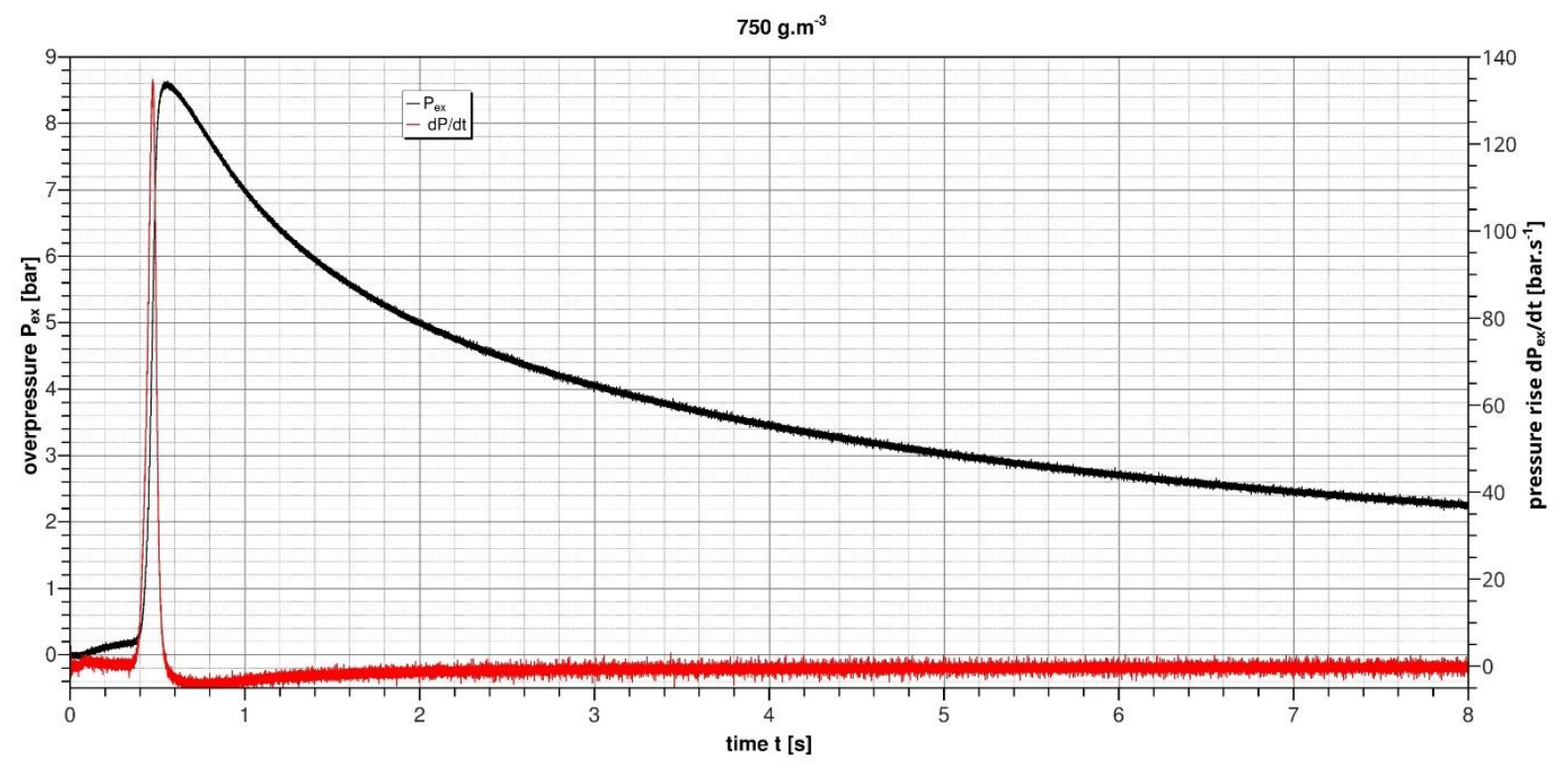

Fig. 2 Determination of the maximum rate of pressure rise of industrial dust sample at concentration 750 g.m.-3

Table 2 shows explosion characteristics of industrial dust clouds at various concentrations. 


\begin{tabular}{|c|c|c|}
\hline \multirow{2}{*}{$\begin{array}{l}\text { Concentration } \\
\left(\mathrm{g} / \mathrm{m}^{3}\right)\end{array}$} & \multicolumn{2}{|l|}{ Sample 1} \\
\hline & Pmax (bar) & dP/dt $\left(\right.$ bar.s $\left.^{-1}\right)$ \\
\hline 60 (att. 1) & 0.36 & - \\
\hline 60 (att. 2) & 0.33 & - \\
\hline 60 (att. 3) & 0.26 & - \\
\hline 100 & 1.42 & - \\
\hline 150 & 3.08 & 6.83 \\
\hline 250 & 6.96 & 59.91 \\
\hline 500 & 8.39 & 69.34 \\
\hline 750 & 8.61 & 134.34 \\
\hline 1000 & 8.49 & 113.32 \\
\hline
\end{tabular}

$$
K_{s t}=\mathrm{d} P / \mathrm{d} t_{\max } \times \sqrt[3]{V}=134,34 \times \sqrt[3]{0,291}=89,0 \text { bar. } \mathrm{s}^{-1} \cdot \mathrm{m}
$$

The minimum ignition temperature of dispersed dust

Table 3 shows the results of determination of MIT of dispersed industrial dust sample of $02 \mathrm{~g}$ and air pressure of 20 and $50 \mathrm{kPa}$.

\begin{tabular}{|l|l|l|l|}
\hline \multicolumn{4}{|l|}{ Table 3 Results of MIT of the dispersed industrial dust sample tests } \\
\hline $\begin{array}{l}\text { Furnace } \\
\text { temperature }\left[{ }^{\circ} \mathbf{C}\right]\end{array}$ & Sample weight [g] & Dispersing air pressure [kPa] & Test results \\
\hline 430 & 0.2 & 50 & burning \\
\hline 430 & 0.2 & 20 & burning \\
\hline 420 & 0.2 & 50 & burning \\
\hline 420 & 0.2 & 20 & without burning \\
\hline 410 & 0.2 & 50 & without burning \\
\hline 410 & 0.2 & 20 & without burning \\
\hline
\end{tabular}

\section{The minimum ignition temperature of dust layer}

Table 4 shows the results of determination of MIT of a $5 \mathrm{~mm}$ layer of the industrial dust sample. Figures 3 and 4 show the measured temperatures of a $5 \mathrm{~mm}$ industrial dust layer at $300{ }^{\circ} \mathrm{C}$ and $310^{\circ} \mathrm{C}$. Figure 5 shows decomposition of the industrial dust sample at $300^{\circ} \mathrm{C}$. 


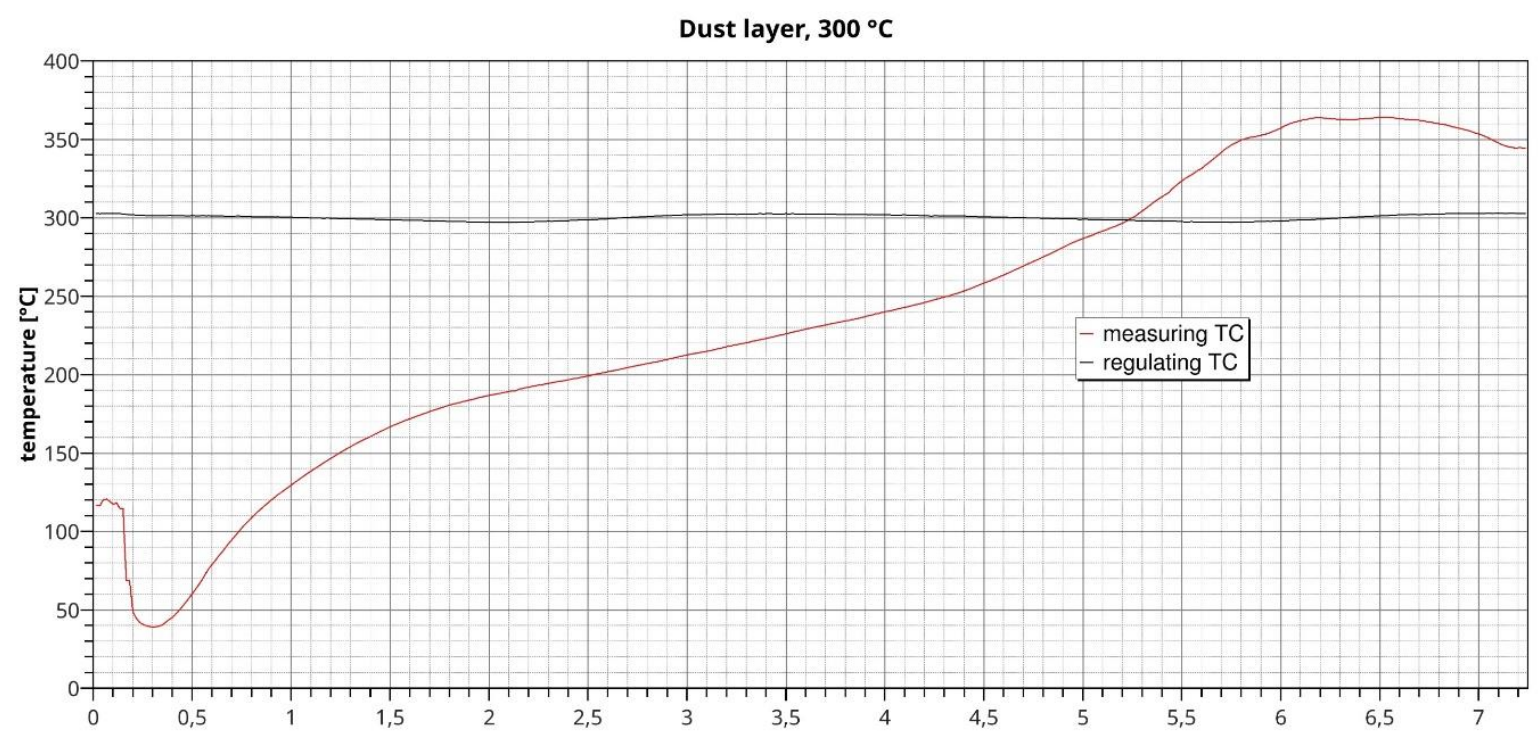

Fig. 3 Measured temperatures of a $5 \mathrm{~mm}$ industrial dust layer at $300^{\circ} \mathrm{C}$

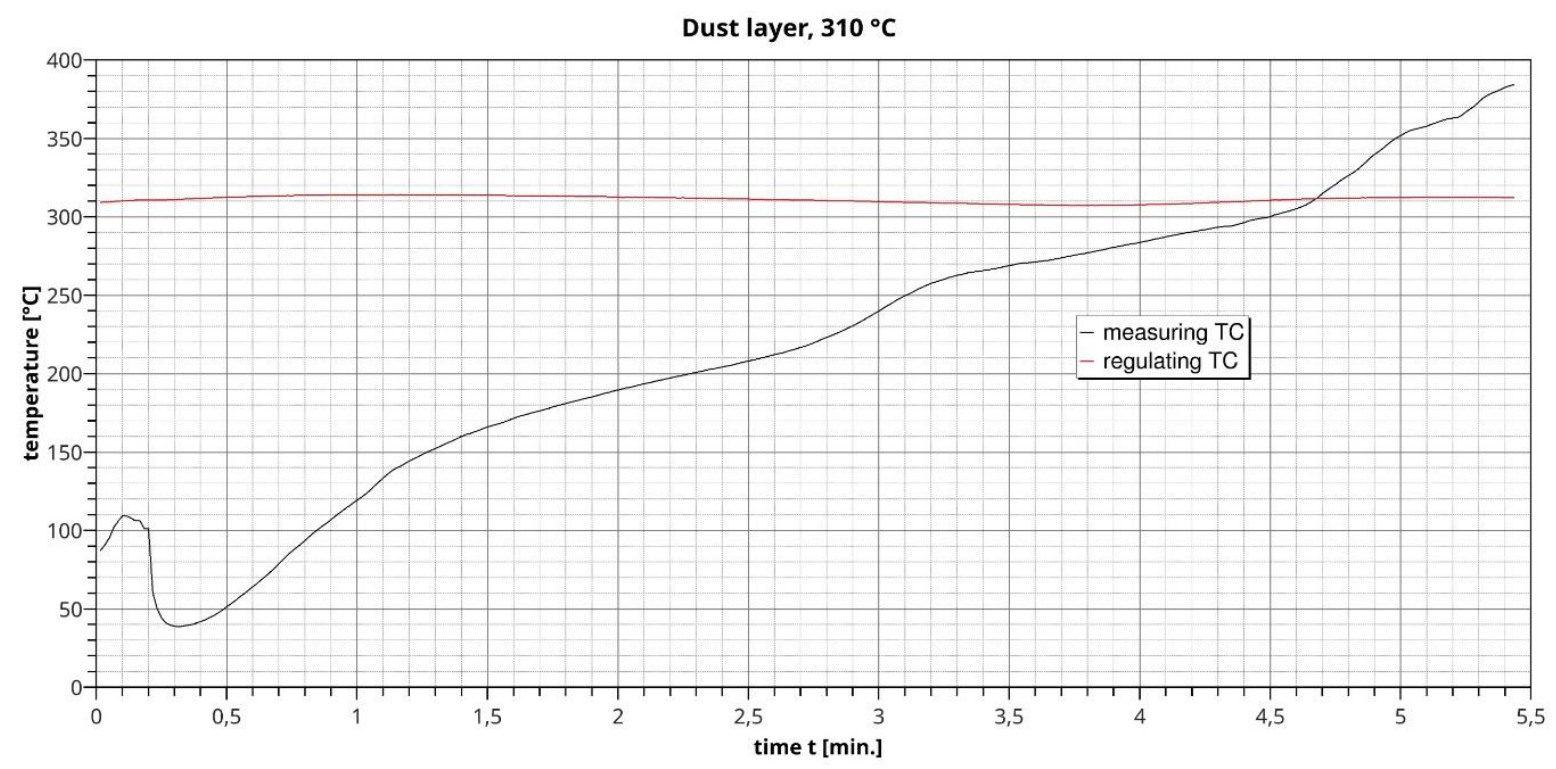

Fig. 4 Measured temperatures of a $5 \mathrm{~mm}$ industrial dust layer at $310^{\circ} \mathrm{C}$

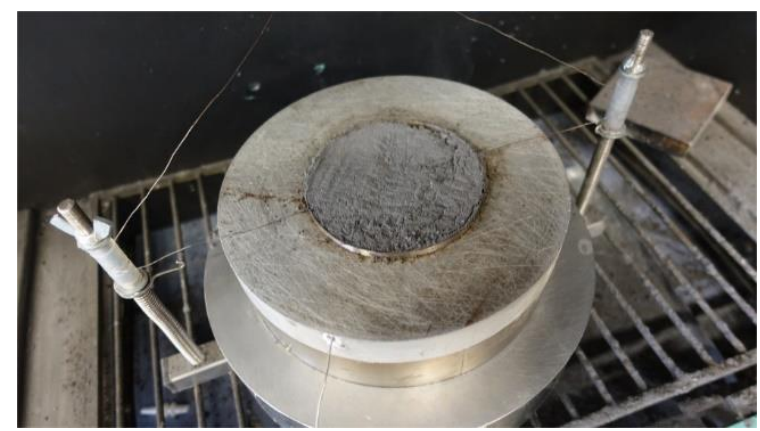

a) Industrial dust layer sample at $300^{\circ} \mathrm{C}$, time $18 \mathrm{~s}$

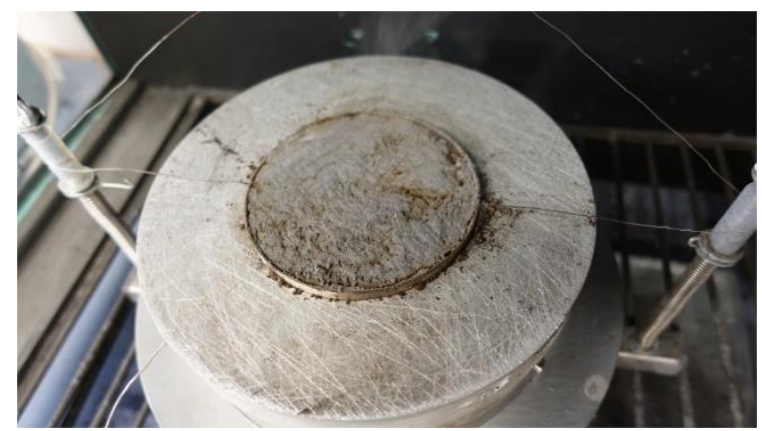

b) Industrial dust layer sample at $300{ }^{\circ} \mathrm{C}$, time 2 min. $54 \mathrm{~s}$ 


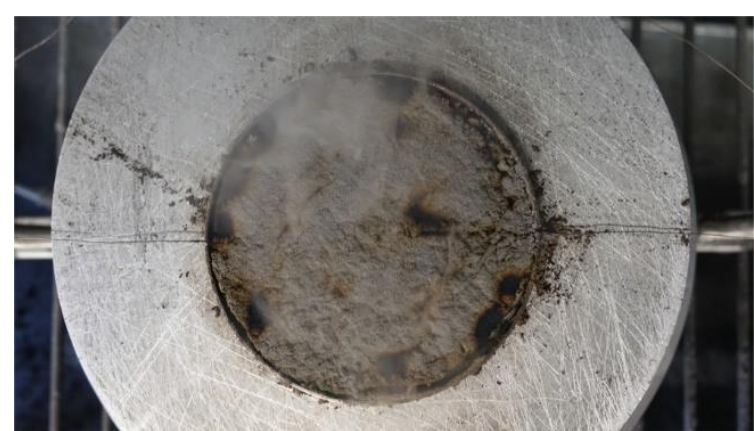

c) Industrial dust layer sample at $300^{\circ} \mathrm{C}$, time 3 min. $51 \mathrm{~s}$

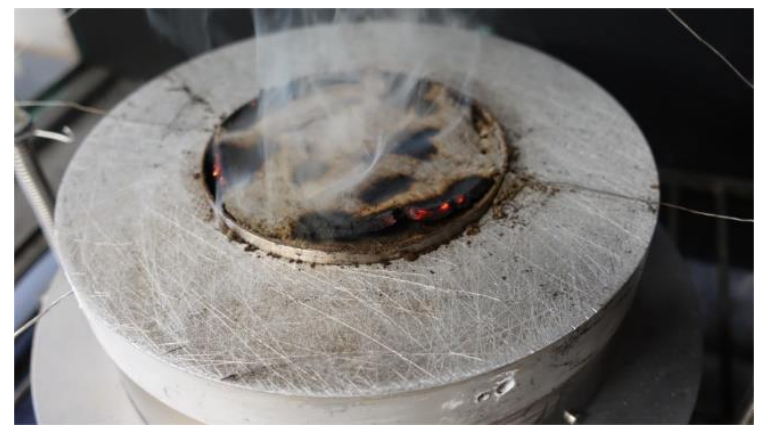

e) Industrial dust layer sample at $300{ }^{\circ} \mathrm{C}$, time 4 min. $34 \mathrm{~s}$

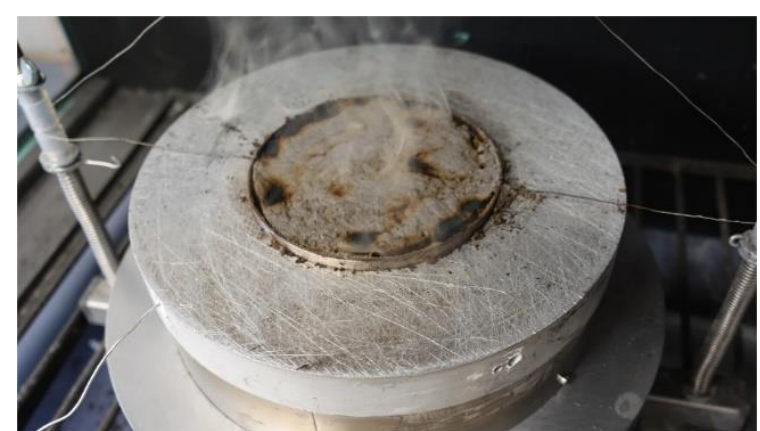

d) Industrial dust layer sample at $300{ }^{\circ} \mathrm{C}$, time 3 min. $57 \mathrm{~s}$

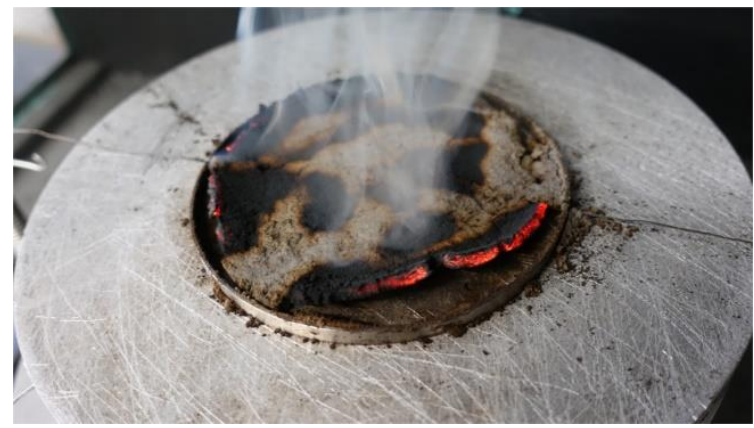

f) Industrial dust layer sample at $300{ }^{\circ} \mathrm{C}$, time 4 min. $59 \mathrm{~s}$

Fig. 5 Decomposition of a $5 \mathrm{~mm}$ sample of industrial dust layer at $300{ }^{\circ} \mathrm{C}$

\begin{tabular}{|l|l|}
\hline Table 4 Results of MIT of $5 \mathrm{~mm}$ layer of an industrial dust sample tests \\
\hline Temperature of heated plate $\left.{ }^{\circ} \mathbf{C}\right]$ & Test Results \\
\hline 270 & Without burning during 30 min. test \\
\hline 280 & Without burning during 30 min. test \\
\hline 290 & Burning after 10 min., $\Delta \mathrm{T}=100 \mathrm{~K}$ \\
\hline 300 & Burning after 5 min., $\Delta \mathrm{T}=190 \mathrm{~K}$ \\
\hline 310 & Burning after 3 min., $\Delta \mathrm{T}=215 \mathrm{~K}$ \\
\hline
\end{tabular}

\section{CONCLUSIONS}

Testing the fire characteristics of an industrial dust sample revealed that the maximum value of the explosion pressure of the sample was attained at the concentration of $750 \mathrm{~g} / \mathrm{m}^{3}$ and its value was 8.61 bar.

Explosion constant $\mathrm{K}_{\mathrm{st}}$ of the industrial dust sample was calculated for the concentration of $750 \mathrm{~g} / \mathrm{m}^{3}$ and its value was 89 bar.s $^{-1} . \mathrm{m}$.

The MIT of the dispersed industrial dust sample was $400{ }^{\circ} \mathrm{C}$ and the MIT of the $5 \mathrm{~mm}$ layer of industrial dust sample was $280^{\circ} \mathrm{C}$.

\section{Acknowledgements}

This research output was supported by the Slovak Research and Development Agency under the contract No. APVV-16-0223 and by the VEGA Project 1/1010/16. 


\section{References}

[1] PÓŁKA, M., WOLIÑSKI, M., KUKFISZ, B., SALAMONOWICZ, Z. 2014. Analysis of susceptibility to ignition of dust layer and dust coud of selected hardened unsaturated polyester resins, Polimery, 59(11-12), 805-810. ISSN 0032-2725

[2] TAVEAU, J. 2014. Application of dust explosion protection systems. Procedia Engineering. 84, 297 - 305. ISSN 1877-7058

[3] AMYOTTE, P. R., ECKHOFF, R.K. 2010. Dust explosion causation, prevention and mitigation: An overview. Journal of Chemical Health \& Safety, 17(1), 15 - 28. ISSN 1871-5532

[4] EBADAT, V. 2010. Dust explosion hazard assessment. Journal of Loss Prevention in the Process Industries. 23, 907 - 912, ISSN: 0950-4230

[5] CHIN, Y. S., DARVELL, L. I., LEA-LANGTON, A. R., JONES, J. M., WILLIAMS, A. 2016. Ignition Risks of Biomass Dust on Hot Surfaces. Energy and Fuels, 30(6), 4398-4404. ISSN 08870624

[6] AJRASH, M. J., ZANGANEH J., MOGHTADERI, B. 2016. Experimental investigation of the minimum auto-ignition temperature (MAIT) of the coal dust layer in a hot and humid environment. Fire Safety Journal, 82, 12-22. ISSN 0379-7112

[7] BO, M., CLERICO, M., POGNANT, F. 2015. Cone-calorimeter tests of rice dusts explosiveness. Geoingegneria Ambientale e Mineraria, 146(3), 15-22. ISSN 1121-9041

[8] EN 14034-3+A1:2012 Determination of explosion characteristics of dust clouds. Part 3:Determination of the lower explosion limit LEL of dust clouds

[9] EN ISO/IEC 80079-20-2:2016 Explosive Atmospheres - Part 20-2: Material characteristics Combustible dust test methods

\section{ORCID}

Zuzana Szabová

0000-0002-7886-1623

Richard Kuracina

0000-0003-1468-0820 